\title{
Reflection of New Graduate Nurses on the Transition Program Conducted in the Selected Malaysian Private Hospitals
}

Aqila SAS, Rabi'atul AS, Annamma $K^{\star}$, Teh Halimaton R and Hamidah $H$

School of Nursing, KPJ Healthcare University College, Negeri Sembilan, Malaysia

\begin{abstract}
Transitions are passages or movements from one state or condition to another, and they can profoundly influence and alter the lives of the individuals involved as well as their significant others such as friends, family, and co-workers. While transitional support programs helps to support the new graduate nurses in their first year of practice, there are unmet needs for clinical, social and emotional support. Understanding new graduate nurses' (NGNs) experiences and their unmet needs during their first year of practice will enable nurse managers, educators and nurses to better support new graduate nurses' attain the new graduates' perception on the Transition Program implemented in three (3) private hospitals. This study is intended to determine the new graduate nurses' (NGNs) reflection towards the transition program in medical, surgical and multidisciplinary wards in the selected private hospitals. The study used a descriptive, cross-sectional design using purposive sampling technique. Reflections on the transition program implemented were assessed using the instrument which was adopted and modified from previous study questionnaires, Hamad Medical Centre (HMC) questionnaires. The Descriptive statistics were employed to express demographic data and reflections of the NGNs towards the transition program. One hundred new graduate nurses with less than three-year experiences participated in this study. The transition program runs in two stages, two weeks for the orientation program followed by six-month preceptor ship. The researchers used a 5-point Likert scale for data collection. Data were analysed using SPSS version 20 . The overall reflection expressed by NGNs on experiences during the transitioning, $70 \%$ agreed and $28 \%$ had strongly agreed the program conducted was well organized. If both results to be combined, $98 \%$ of respondents reflected excellence for the transition program conducted. In conclusion, the transition program which comprised of orientation and preceptor ship program is the most significant approach of helping the adaptation of the NGNs working in the clinical environment. Thus, these programs should be regularly conducted in every hospital which indirectly helps in decreasing the rate of turnover among the NGNs.
\end{abstract}

Keywords: Reflection; Newly graduates nurses; Transition program; Orientation program; Preceptor ship program; Private hospitals

\section{Introduction}

To fully comprehend the transitional experiences of new graduates, it is vital to be aware of their clinical environment and workplace conditions. A positive workplace environment facilitates a more effective transition of graduate nurses and significantly influences their job satisfaction [1]. Adverse experiences have been found to result in feelings of heightened work stress for up to one year after graduation, with contributory factors including poor work environments, poor clinical supervisors and poor nurse-doctor relations to the new graduates coming into the new places of work [1].

Transition means anytime someone makes a 'change' from what they know to what they do not know or are not entirely familiar with; they experience a transition a journey from what was to what is [2]. Besides, a transition as passages or movements from one state or condition to another, and they can profoundly influence and alter the lives of the individuals involved as well as their significant others friends, family, and co-workers [3]. However, the transition also begins with events that create instability and make the change necessarygraduating as a nurse and moving from being a nursing student to a fully responsible professional nurse is such an event [4-6].

First years of professional practice is the most stressful time, and NGNs rely on peer nursing support for longer than a year of initial employment [7]. The new graduate nurses' described their experiences in the first year of practice as overwhelming and stressful as they strive to apply newly acquired skills, deliver quality patient care and 'fit in' [8]. Importantly, in the first year of practice is also a time of high attrition with rates of up to $27 \%$ reported in the literature. These concerns have contributed internationally to the development of new graduate programs, often referred to as transitional programs, to promote clinical proficiency, support new graduate nurses' (NGN) professional development and improve retention.

New graduate nurses face a host of challenges that impact the successful transition to practice. Healthcare organizations thus need to understand how changes in the healthcare landscape impact new graduate nurses who are transitioning to the practice environment [5]. To ensure a successful transition from a novice nurse to competent registered nurse (RN), structured professional development programs are provided in a supportive manner to help newly graduated nurses integrate into organizational systems and processes.

A good orientation program has been beneficial to students, new staff and anyone who are new to the place. Many literatures support this fact [9-11]. The newly developed orientation system was successful in achieving a high satisfaction level among pharmacy staffs in different aspects.

*Corresponding author: Annamma Kunjukunju, KPJ Healthcare University College, Lot PT 17010, Persiaran Seriemas, 71, 800, Kota Seriemas, Nilai, Negeri Sembilan Darul Khusus, Malaysia, Tel: 606-7942131/2632; Fax: 606-7942662; E-mail: ann@kpjuc.edu.my; annjoe212@gmail.com

Received September 19, 2018; Accepted March 09, 2019; Published March 16 2019

Citation: Aqila SAS, Rabi'atul AS, Annamma K, Teh Halimaton R, Hamidah H (2019) Reflection of New Graduate Nurses on the Transition Program Conducted in the Selected Malaysian Private Hospitals. J Pat Care 5: 144. doi: 10.4172/25734598.1000144

Copyright: (C) 2019 Aqila SAS, et al. This is an open-access article distributed under the terms of the Creative Commons Attribution License, which permits unrestricted use, distribution, and reproduction in any medium, provided the original author and source are credited. 
Besides from orientation, preceptorship program also plays a vital role during the transition from student to newly registered nurse (RN). There are seven studies discussed the importance of preceptors which include improvement in new graduate critical thinking, quality care, new graduate satisfaction with their preceptor experience, and new graduate retention [12].

While transitional support programs may aid new graduate nurses in their first year of practice, there are unmet needs for clinical, social and emotional support. Understanding new graduate nurses' experiences and their unmet needs during their first year of practice will enable nurse managers, educators and nurses to better support new graduate nurses' and promote confidence and competence to practice within their scope. Thus, the study aims to determine the new graduate nurses' (NGNs) reflection towards the transition program in medical, surgical and multidisciplinary wards in the selected private hospitals.

Specifically, the study intended to: (1) determine the satisfaction level of the NGNs towards the implemented transition program, (2) determine to which extent the orientation and preceptor ship program assist the NGNs in adapting in real workplace, (3) determine the differences of reflection between NGNs working in the medical, surgical and multidisciplinary wards.

\section{Background}

Kumpulan Perubatan Johor (KPJ) group of Hospital is one of the largest and well-known private hospitals in Malaysia.

The transition program in this study means that every new nurse who comes to work in selected hospitals will have to go through a structured transition process. For the first two (2) weeks the new nurses will undergo a program known as an orientation program and followed by another program called preceptor ship.

The orientation program has long been recognized as one of the essential support to successfully transition program [13]. An orientation program is a program designed to orient new employees to the new working environment and to develop clinical and social skills [14]. The time frames for orientation vary depending on the area of work, but usually, the orientation will be two weeks at the medical, surgical and multidisciplinary (medical and surgical cases) wards. New graduates who received a more extended orientation that met all of their needs were more satisfied in their current position [13]. The orientation program for nurses should incorporate several aspects such as simulation, clinical competencies, and education time.

The components of the orientation program include central orientation and Unit-based orientation. The central orientation is organized by the Talent Management (Human Resources) of the organization for all the new staff to orient them to the hospital system and standard operating procedures of different departments within the organization. Conversely, the unit orientation is mainly for informing the new graduates regarding the system and process of the specific units.

This six (6) months preceptor ship program supports the new nurses to get adjusted to a new environment, new experiences and new tasks and responsibilities to be carried out. Preceptor ship is a period of practical experience and training for students or new graduates which is supervised by an expert or specialist in a particular field [15]. While preceptor ship as a standard type of one-to-one resource available for new graduate nurses within a formal transition program [16]. Preceptor ship is one of the components of the current transition program which can increase clinical support, help consolidate skills/ knowledge and encourage professional socialization [17]. A Preceptor is assigned to each new staff, and individualized preceptor ship provided for first the six (6) months. Preceptors are chosen based on seniority, and a post basic qualification in the respective specialty is considered as an added advantage to be appointed as the preceptor. Preceptor ship training is also provided to all the preceptors. During the Preceptor ship, the new graduates are expected to shadow the preceptor. Initially, the new graduate will be an observer or pair of additional hands. Gradually over the period of six-month graduates becomes more proficient and are allowed to handle patient care with more independence. During the preceptor ship, the new graduates are required to complete credentialing requirements of the organization and competency check to certify to be safe healthcare practitioners. The preceptor also requires to give feedback to the new graduates on a regular basis and evaluate the overall performance of the new staff. If the performance within six (6) months is evaluated as not satisfying the new graduate's probation is extended with more extended preceptor ship period up to nine (9) months or one (1) year.

\section{Problem statement}

The new nurses are expected to be competent performers in the respective clinical discipline upon graduation; there is no doubt about it. However, it is essential for institutions to design a transition program to meet the unique needs of novice nurses. As these NGNs have undergone a very long period of training; three (3) years for the Diploma in Nursing and four (4) years for the Bachelor of nursing programs, a period of determining of the specific knowledge and skills. It is therefore desirable for each institution to have a special program to help the new nurses to consolidate the knowledge and skills in the real workplace and to ensure the safety of the patients, as well as the integrity of the organization.

Sometimes the orientation program is forgotten or not taken seriously because of the constant bustling of the clinical environment lack of staff to carry out the task makes the transition program neglected. Many organizations are frequently short of staff and are expecting the new nurses to effectively function as a nurse, providing patient care, within a short amount of time [17]. The new nurses are entering the healthcare field, receiving an abbreviated orientation, and then expected to take on a full patient assignment [18]. This experience is setting them up for failure. The unprepared novice nurses become frustrated, and eventually, they will leave the profession.

As a new staff, they may not be able to express much but to follow the instructions on the job given even if it is in as ambiguity situations. Majority of the new graduates expected a tough job to be encountered with the absence of proper guidance and admonishment if mistakes are made [19]. However, there are some institutions which had never missed the transition program consecutively to all their new staff, but never bother about the effectiveness of the implementation. Thus, it would be no different if the program is implemented but unconcerned directly on the effectiveness of its implementation [20]. Retention of staff on the ward also highly correlated with having a program, satisfaction, adaptation, and support experienced more heavy responsibilities than expected, fragmentation of patient care, and stressful interactions with colleagues, lack of a supportive work environment and role models.

The researchers had done some general observation on the implementation of the transition program from the general wards of medical and surgical wards of the selected private hospital before this study was conducted. Although the program has always been conducted 
every time they received new graduates, there were complaints from the NGNs against their dissatisfaction on the implementation of the program.

The following research questions developed for the study;

1. What is the overall NGNs' satisfaction towards the implemented transition program?

2. To which extent the orientation and preceptor ship program assist the NGNs in adapting in real workplace?

3. What are the differences of satisfaction level between NGNs working in the medical, surgical and multidisciplinary wards?

\section{Methods and Materials}

\section{Research design}

This is a cross-sectional study with self-administered questionnaires conducted in medical, surgical and multidisciplinary (medical and surgical) wards from the selected private hospitals.

\section{Participant / Population and sampling technique}

Respondents for this study were selected within private hospital in Klang Valley which is under the same organization and province. Selection of respondents was based on purposive sampling on the criteria where the NGNs (new graduate nurses) with less than three (3) years of working experiences.

\section{Sample size}

The total number of respondents in this study was 100 which were calculated based on the previous study [20].

\section{Inclusion criteria}

- Newly graduate nurses (NGNs) who work in the selected hospitals in medical, surgical and multidisciplinary wards.

- Respondents who have working experience within the first three (3) years.

- Respondents who had undergone the orientation and preceptor ship program.

\section{Exclusion criteria}

- NGNs that work in other ward in the selected KPJ Hospitals such as pediatric ward, maternity ward, accident and emergency, operation theatre, and else.

- NGNs that had more than 3 years of working experience.

- NGNs that did not completed the orientation and preceptor ship program.

- NGNs those were not available during the data collection and unwilling to give consent.

- Incomplete questionnaires were omitted from data analysis.

\section{Instrumentation}

Questionnaire from Hamad Medical Centre (HMC) was adapted, modified, validated, and piloted by the researchers to outfit the study. A written permission through email was obtained to use the tool for the study.

The questionnaires measuring the reflections of the NGNs towards the Transition Program through 5 points of Likert scale ranging from strongly agree to strongly disagree. Those items will indicate the level of satisfactory of NGNs towards the Transition Program.

\section{It consists of:}

Part A: 16 items on the reflection of the NGNs related to the Orientation program and Preceptor ship program

A (1) is a set of questionnaires on the Orientation Program that runs for two weeks for the new graduates, starting from the day of reporting till the $14^{\text {th }}$ day working in that particular wards.

$\square$ The questions comprise of 5 items with 5 Likert scale from strongly agree to strongly disagree.

A (2) is a set of questionnaires on the Preceptor ship following the two-week completion of the Orientation program till the end of the sixth month working as a new graduate in that particular wards.

$\square$ The questions comprise of 11 items with 5 Likert scale from strongly agree to strongly disagree.

$\square$ Part B: 10 items of demographic data.

There were 16 questionnaires in the form of measurement scale which directed the NGNs to indicate on a 5-point Likert scale with " $1=$ strongly disagree" to " $5=$ strongly agree". This scale was used to analyse the NGNs reflection toward the transition program during their working in medical, surgical, or multidisciplinary ward.

\section{Ethical consideration}

Ethical approval was obtained from the Ethical Committee of KPJUC dated $15^{\text {th }}$ December 2017 and approval for conducting a study at relevant selected hospitals was also obtained.

Issues such as verification of instrument used versus subject to be measured had been rectified during the ethical clearance session. The questionnaires measuring the reflections of the NGNs towards the Transition Program will also indicate the level of satisfactory of NGNs towards the Transition Program.

\section{Data collection process:}

Questionnaires had been distributed personally by the researcher themselves to 100 respondents of newly graduated nurses (NGNs) who worked in the medical, surgical and multidisciplinary wards from the selected hospitals.

$\square$ The content was explained clearly, and the confidentiality and anonymity of the data were ensured.

$\square$ Each session held within $15-30$ minutes in duration and it was done to suit the respondents' convenient time.

$\square$ Data collected were kept storage at dedicated boxes and was kept in locked drawer in the researchers' room.

\section{a. Data analysis:}

The collected data was analyzed using Statistical Package for Social Science (SPSS) version 20. Descriptive statistic was used to analyze the demographic data. Correlation and Kruskal-Wallis analysis were used to analyze the data collected following the objectives of the study (Table 1).

\section{Results}

The demographic data demonstrates the distribution of 100 new graduate nurses (NGNs) regarding the school of nursing attended, 
duration of working experience, duration of orientation, number of preceptors and working area.

The respondents comprise of majority from KPJ Healthcare University College (KPJUC), and 50\% of them are working at less than one (1) year. The result showed, there is no significant relationship between the training center and duration of working experience reflected by the new graduate nurses during the transition period. Thus, NGNs' reflection is nothing to do with the training center and duration of working experience, whereas it is affected by individual attitudes such as NGNs' confidence level.

Every new graduate nurses will have an orientation program and followed by a preceptorship program. For the orientation program, the majority of the NGNs will have experience two (2) weeks of getting to know the new place, the new people and the routine of the working place. Upon completion of the orientation programme, a preceptorship program is offered by the qualified preceptors to assist the NGNs in transforming from students status to qualified nurse within six (6) months depending on the competency of individual NGNs. Majority of the respondent has only one preceptor. Lastly, all of the respondents have been working in the medical, surgical or multidisciplinary ward. A Kruskal-Wallis test [21] showed that there was no statistically

\begin{tabular}{|c|c|c|c|}
\hline Variables & Value & $\begin{array}{c}\text { Number of } \\
\text { respondents } \\
\text { (N=100) }\end{array}$ & $\begin{array}{c}\text { Valid Percent of } \\
\text { respondents (\%) }\end{array}$ \\
\hline Training Center & KPJUC & 84 & $84 \%$ \\
\hline Duration & 12 months and below & 16 & $16 \%$ \\
\hline & 13 to 24 months & 28 & $53 \%$ \\
\hline Orientation & 25 to 36 months & 19 & $28 \%$ \\
\hline & Still ongoing & 3 & $19 \%$ \\
\hline & $<8$ weeks & 90 & $90 \%$ \\
\hline Preceptor & $9-12$ weeks & 7 & $7 \%$ \\
\hline & One & 75 & $75 \%$ \\
\hline & Two & 17 & $17 \%$ \\
\hline & Three & 7 & $7 \%$ \\
\hline Working area & Four & 1 & $1 \%$ \\
\hline & Medical & 31 & $31 \%$ \\
\hline & Surgical & 37 & $37 \%$ \\
\hline
\end{tabular}

Table 1: The demographic data demonstrates the distribution of 100 new graduate nurses (NGNs) regarding the school of nursing attended, duration of working experience, duration of orientation, number of preceptors and working area. significant difference in NGNs' reflection either in the medical, surgical or multidisciplinary wards during the transition programs.

Figure 1 shows the majority of the respondents were satisfied with the orientation program provided by the hospital management. For the Statement $1,67 \%$ of respondents agreed that orientation to the site was adequate. The same goes for Statement 2, 70\% of respondents agreed that orientation to the site was well organized and $26 \%$ strongly agreed that the program conducted during their transition process was well organized.

While there were $61 \%$ of respondents agreed with Statement 3 which is their colleagues were receptive and willing to interact with them. A total of $69 \%$ of respondents agreed with the Statement 4 and $68 \%$ for Statement 5 which is they agreed that the site provided an opportunity for applying knowledge and had gained adequate experience from the orientation (Figures 2 and 3 ).

Table 1 presents the respondents' degree of agreement on the statements related to preceptor ship and working environment. A total of $64 \%$ of respondents agreed with the statements $6,14,15$ and 16 which is their preceptor demonstrated an interest in orienting them, received the recognition they deserved whenever delivered a good job, and like the people they work with and agreed that communication seems reasonable within the unit. For statement 7 and 8, 65\% of respondents agreed that their preceptor spent adequate time, willing to help them when in need and explained and clarified information for them. From statement 9, 11 and 12, a total of $62 \%$ respondents agreed that their preceptors encouraged them to ask the question, solving the problem and make a decision under supervision; provided positive criticism on interpersonal skills with staff and patients whenever needed, and displayed professional attitude and motivation. $67 \%$ respondents agreed with the Statement 10 which are the preceptors were enthusiastic, competent, and knowledgeable in their area of practice and $60 \%$ of respondents agreed with Statement 13 which is the preceptors served as a good role model to them. Overall, the majority of respondents in the ranges of $60 \%$ to $67 \%$ agreed with the statements about preceptor ship and their working site.

\section{Discussion}

The aim of this study was to determine the new graduate nurses' (NGNs) reflection towards the transition program in medical, surgical and multidisciplinary wards in the selected private hospitals. Overall reflections of new graduate nurses' experiences on transitioning from student to a registered nurse are excellent. The average of each proposed

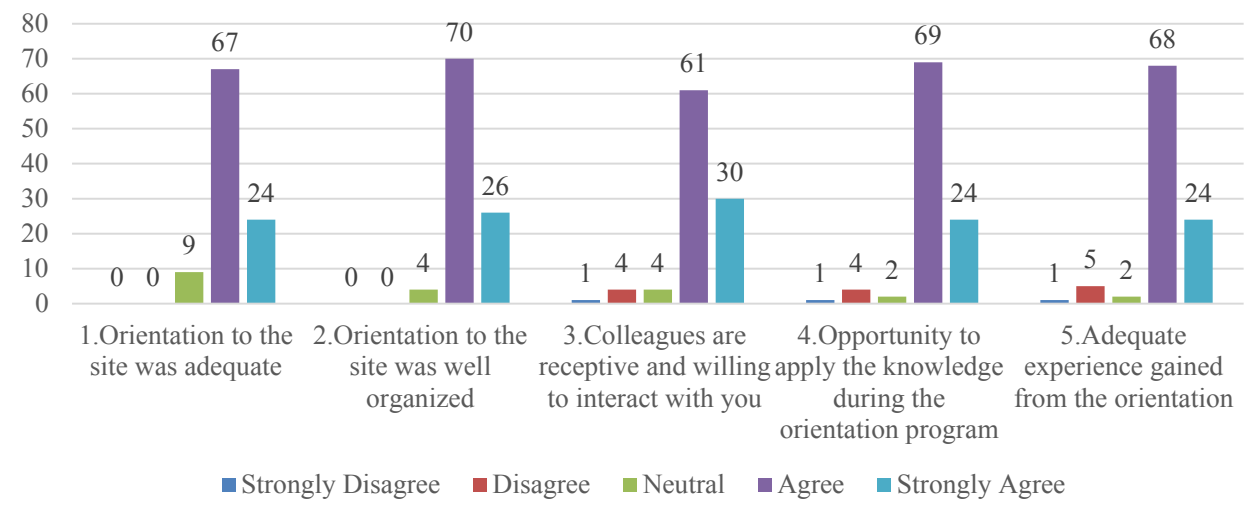

Figure 1: Reflection of NGNs on the orientation program. 


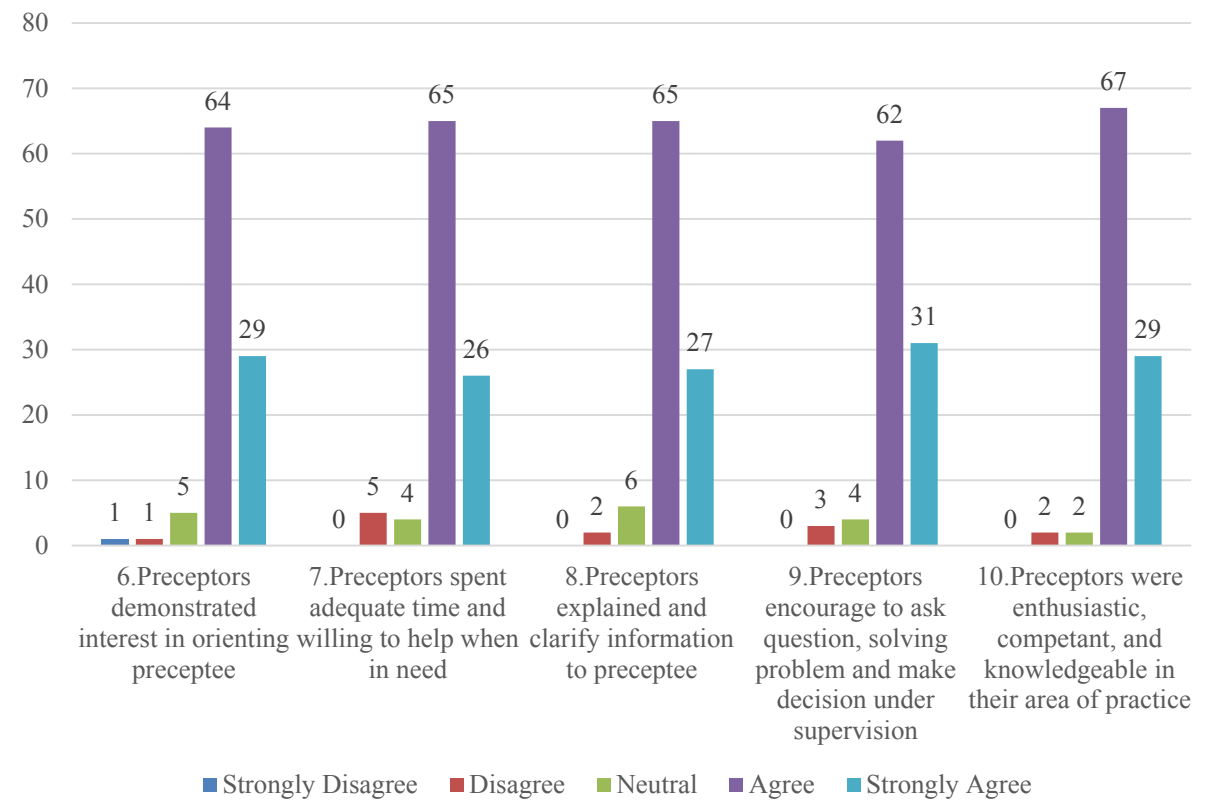

Figure 2: Reflection of the NGNs towards the preceptorship program.

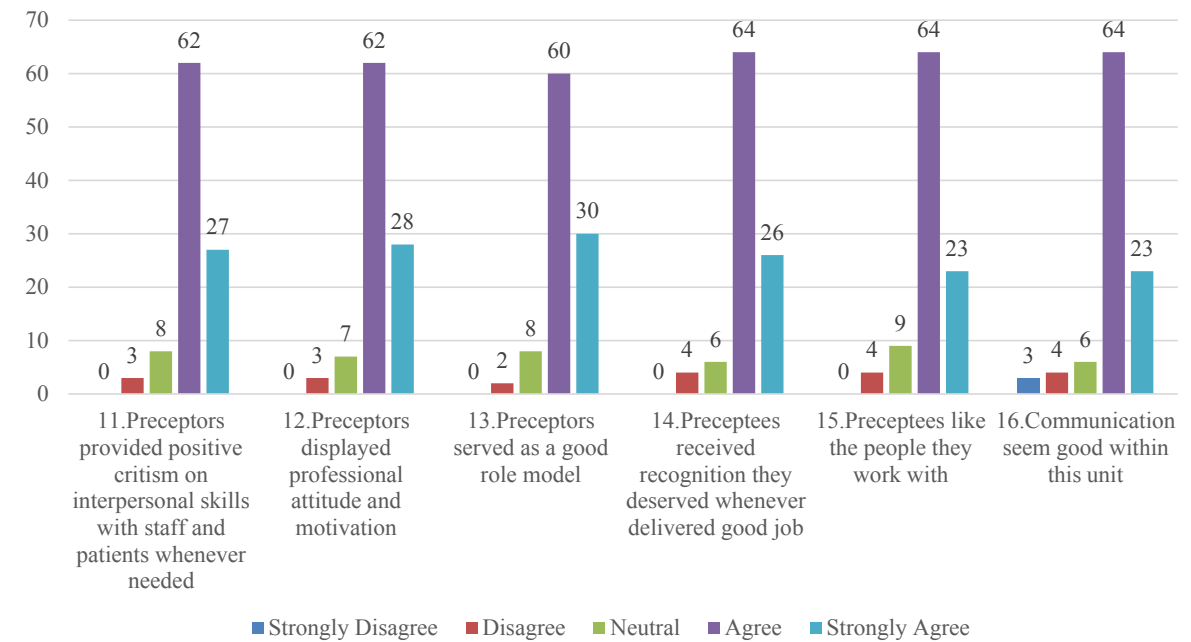

Figure 3: Reflection of the NGNs towards the preceptorship program.

questionnaire was calculated with a positive answer. The new nurse's reflections between strongly agreed and agreed are closely linked to positive components and consistent reflections given throughout the process of transition program implemented. This shows the process of transition program which composed of orientation and preceptor ship program undertaken by the selected hospital was effective.

The preliminary process of building a nurse's confidence through the orientation program was also respectably agreed by the new graduates all through the orientation process.

The above statement by the researchers has a similar opinion from a previous study [22]. They believed any orientation program deliberately designed to meet the educational needs of the new nurses during their transition to practice, instilled the confidence and competence level upon entering the clinical setting, standardize orientation, and stabilize retention. Being a newcomer, they often look forward to a situation that provides firm support during the transition process, so that they are on the right track and there are no errors occurs. The supportive relationships were reported to facilitate confidence especially in interprofessional collaboration and constant support from the preceptors and mentors and organizational leaders.

In the reflection made by the 100 respondents of this study, on the orientation program conducted, $70 \%$ agreed, and $26 \%$ strongly agreed that the program conducted during their transition process was well organized. If the researchers were to takes into consideration between agreed and strongly agreed as one cut off point of 'agreed 'then, the percentage agreeing is $96 \%$. This is a great achievement for those three hospitals and congratulations for taking into account the importance of the newcomers,' matters of concerned.

What has led to the excellent performance achieved by those hospitals in the implementation of the orientation programs for their 
new nurses? The researchers had believed that there is a strong link with the recommendations made by most of the literature around the world about the importance of orientation programs for the new graduates. The following facts have been retrieved from the pieces of literature since 1999 [23]. Many kinds of literature had mentioned the orientation programs had encouraged the new nurses to feel welcome, safe, valued and nurtured eases the transition and enhances their overall satisfaction. The importance of a supportive practice environment for new graduates, such as an orientation program addressed the needs of the new graduate's for belonging and security and placing socialization as the first organizational goal. It also contributes to positive role adjustment; key supports to ease the transition and encourage nurse's retention to lead the access to continuing their education opportunities.

In this study, the majority of respondent had duration of below than eight (8) weeks for their orientation; they had been working in the medical, surgical or multidisciplinary wards. They received extensive experience in medical and surgery units, especially in the recovery process. More than $67 \%$ of the respondent agreed that orientation was adequate and well organized with a high level of agreement expressed on the satisfaction by NGNs and the respondent agreed that during orientation program, the staff nurses from both disciplines were receptive and willing to interact with the new graduates.

The respondents of this study had reported that they have the opportunity to apply their knowledge and gained experience from the orientation program provided and the majority of them were satisfied with the orientation system [20,24]. Structured orientation program affects adaptation, satisfaction, and support of the graduate nurses on the ward.

The structured orientation program implemented in this study start from the first week of orientation program which focused on (i) central orientation program (COP), and (ii) service orientation program (SOP). COP is the introduction of organization's overall culture in the hospital. While, SOP is done on the second week which introduce the specific department or unit by the unit manager itself.

Later, followed by the first six (6) months program called, a preceptor ship program which conducted by qualified preceptors. Those preceptors are ready to guide the new graduates in the management of patient care, nursing procedures, and the wards routine. The main focus of the program is to ensure the new graduates are safe to patient safety and excellent quality of work.

As for the preceptor ship program, more than $90 \%$ of the respondents had agreed/strongly agreed that the preceptors had spent adequate time with them and the preceptors were available and willing to help them, explained and clarified information, encouraged to ask questions, help in solving problems and make decisions under supervision.

In this study the new graduates regarded the highest score among the item of preceptorship was "the preceptors were enthusiastic, competent and knowledgeable in their areas of practices, besides encouraging the new graduates to ask questions, assist them in solving the problems and make decisions [25]. Personal characteristics included empathic, warm, respectful, and humorous. Flexibility, fairness, dependability, consistency, and enthusiasm were valued. New graduate nurses (NGNs) also looked favourably on preceptors who were willing to work with the beginning staff, could adapt their teaching style as needed, and supported the educational program. The preceptor is expected to have current clinical skills and knowledge, help staff recognize their assumptions and think through their management decisions, and model effective communication with patients that emphasize.
However, in this study $75 \%$ respondents preferred with only one preceptor to provide the supervision throughout the program, in most of the time, the change of too many preceptors may be due to busyness and the availability of preceptor in the ward. Of course, new graduates will feel confident and comfortable when having supervisors or instructors who are familiar with them from the beginning.

Individual attributes - personal and professional strengths and weaknesses; professional behavior - actions such as engaging help and support, advocating for patients' needs and safety and putting their feelings aside; situational challenges such as communication difficulties, both systemic and interpersonal, and the pressure of competing demands [24]. At the end of the program, the new graduates will be measured by their ability to perform safe nursing tasks based on checklist and question and answers.

New graduates also identified rewards - results they experienced such as achieving the nursing outcomes they desired and commented on reflection as a useful tool. The findings shed light on the experiences of new graduates, and how they fare through this critical phase of career development.

Transition to practice is an important stage in the development of a professional registered nurse [26]. Lack of time appears to be a significant hindrance in the transfer of learning by preceptors, there is a need for practice areas, to re-evaluate their commitment to preceptor development and their role in supporting new nurses' learning [27]. There was an indication among studies reviewed that nurses were satisfied with their learning experiences during preceptor ship while their confidence in undertaking clinical tasks had increased. However, early 3-4 months of professional role transition for the newly graduated nurse as a process of change that is developmental, intellectual, sociocultural and physical and which is both motivated and mediated by changing roles, responsibilities, relationships and levels of knowledge in the personal and professional lives of the new professionals [28].

In one study, nurses involved in a preceptor ship program where preceptors had been trained had a high graduation rate, while the pass rate for nurse registration examination for this group was higher compared to the national mean.

The study also showed that there was no significant difference in NGNs' reflection either in the medical, surgical or multidisciplinary wards during the transition program. The reason for the insignificance could be due to standardized transition programs developed and implemented by trained preceptors of each hospital involved in this study. Unpreparedness of the new graduates can have great consequences in the safe practice of healthcare system [29]. Graduate nurses experience stress transitioning from student nurse to registered professional nurse where role expectations are to rapidly function as a competent nurse $[30,31]$.

\section{Limitation of the Study}

- For the data collection in this study, the NGNs answered the questionnaires during their working time, so the result may affect by their emotional and surroundings which also affect the researchers' study. There is no suitable time for the researchers to collect data as the NGNs fully commit to their work in the wards.

- This study was conducted at the selected private hospital only. Thus it leads to the small study population which makes it 
Citation: Aqila SAS, Rabi'atul AS, Annamma K, Teh Halimaton R, Hamidah H (2019) Reflection of New Graduate Nurses on the Transition Program Conducted in the Selected Malaysian Private Hospitals. J Pat Care 5: 144. doi: 10.4172/2573-4598.1000144

difficult for generalization of the result. The small sample size imposes limits to one's ability to generalize to larger populations.

\section{Recommendations}

There were few recommendations made for further research interest of the new graduates' transition period. Study involving a larger and representative random sample of nurses from both private and public hospitals can be investigated. Another study could be developed on comparative research to improve the nursing practice outcomes between other private hospitals within the country.

For those international newly graduate nurses who has intention of working globally especially in Malaysia will have a better platform to start the career.

\section{Conclusion}

The study on the newly graduate nurses' (NGNs) reflection towards the transition program in the selected Malaysian Private Hospitals had given the institutions remarkable evidence that the implementation of the program was excellence. This could be a benchmark or a model for other health training institutions to adopt. However, improvement could be done to achieve further excellence especially in the aspect of training of the preceptors as a role model.

\section{References}

1. Hussein R, Everett B, Ramjan L, Hu W, Salamonson Y (2017) New graduate nurses' experiences in a clinical specialty: A follow-up study of newcomer perceptions of transitional support. BMC Nursing 16: 42.

2. Boychuk Duchscher J (2012) Navigating the first year of professional nursing practice. Published by: Nursing the Future, PO Box 22058, RPO Wildwood, Saskatoon SK, Canada, and S7H

3. Bjerknes MS, Bjørk IT (2012) Entry into nursing: An ethnographic study of newly qualified nurses taking on the nursing role in a hospital setting. Nursing Research and Practice $\mathrm{Pp}: 1-7$.

4. Chang E, Daly J (2012) Transitions in nursing: Preparing for professional practice, 3rd edn, Elsevier, Chatswood.

5. Hofler L, Thomas K (2016) The transition of new graduate nurses to the workforce: Challenges and solutions in the changing health care environment. N C Med J 77: 133-136.

6. Kaihlanen AM, Lakanmaa RL, Salminen L (2013) The transition from nursing student to registered nurse: The mentor's possibilities to act as a supporter. Nurse Educ Pract 13: 418-422.

7. Peterson R, Berns S (2005) Developing clinical competencies/ training checklists: When you have to start from scratch. J Nurses Staff Dev 21: 291294.

8. Wong Pei Y, Noor Rehan ZA, Noor Hisham M, Annamma K, Hamidah H (2017) Structured clinical teaching initiatives: A preparation for first year nursing students as first timer in the clinical placement. J Nurs Care: 6: 435.

9. Hamidah H, Maziah M, Ayesha B, Subahan T, Rahayah, A (2012) The Development of a Malaysian Model Internship Programme (MyMIP): A preceptor model for nurses in their early stage of profession. Proc Soc Behav Sci 64: 492-500.
10. Hezaveh M, Rafii F, Seyedfatemi N (2013) Novice nurses' experiences of unpreparedness at the beginning of the work. Glob J Health Sci 6: 215-222.

11. Al Zaidan M, Al Siyabi K, Ibrahim MI, Saad A, Rustom F, et al. (2017) Perceptions and satisfaction of pharmacy staff towards the orientation program at the specialized hospitals in Qatar: A cross-sectional study. J Appl Pharm 9: 3

12. Hamidah H, Annamma K (2018) A follow-up study: New nurse graduates performance evaluation in a familiarized nursing environment when everything is new to everyone. J Nurs Care 7: 456.

13. Phoenix Bittner N, Gravlin G, MacDonald C, Bourgeois D (2017) A newly licensed nurse orientation program. J Contin Educ Nurs 48: 22-28.

14. Ivey J (2012) The transition from student to nurse: The orientation process (Master of Science in Nursing (MSN). Gardner-Webb University.

15. The definition of preceptorship 2018.

16. Rush K, Adamack M, Gordon J, Lilly M, Janke R (2013) Best practices of formal new graduate nurse transition programs: An integrative review. Int J Nurs Stud 50: $345-356$

17. Baxter PE (2010) Providing orientation programs to new graduate nurses: Points to consider. J Nurses Staff Dev 26: 12-17.

18. Lalani N, Dias $\mathrm{J}(2011)$ The role transition of nurses in a university teaching hospital in Pakistan. J Nurses Staff Dev 27: 1-5.

19. Pfaff KA, Baxter PE, Jack SM, Ploeg J (2014) Exploring new graduate nurse confidence in inter-professional collaboration: A mixed methods study. Int J Nurs Stud51: 1142-1152.

20. Strauss E, Ovnat C, Gonen A, Lev-Ari L, Mizrahi A (2016) Do orientation programs help new graduates?. Nurse Educ Today 36: 422-426.

21. Kruskal WH, Wallis WA (1952) Use of ranks in one-criterion variance analysis. J Am Stat Assoc 47: 583-621.

22. Dellasega C, Gabbay R, Durdock K, Martinez King N (2009) An exploratory study of the orientation needs of experienced nurses. J Contin Educ Nurs 40 311-316.

23. Noseworthy T, Harnet $L$ (2002) Orientation programs for registered nurses: Best practice guidelines. Association of registered nurses of new found land and Labrador Pp: 1-24.

24. Evaluation: Focus on Outcomes. J Cont Educ Nurs 48: 22-28.

25. Gilmour J, Huntington A, Slark J, Turner C (2017) Newly graduated nurses and employment: A dynamic landscape. Collegian 24: 247-253.

26. Burns C, Beauchesne M, Ryan Krause P, Sawin K (2006) Mastering the preceptor role: challenges of clinical teaching. J Pediatr Health Care 20: 172-183.

27. Ankers M, Barton C, Parry Y (2017) A phenomenological exploration of graduate nurse transition to professional practice within a transition to practice program. Collegian 25: 319-325.

28. Kamolo E, Vernon R, Toffoli L (2017) A critical review of preceptor development for nurses working with undergraduate nursing students. Intern J Care Sci 10 1089-1100.

29. Boychuk Duchscher J (2009) Transition shock: The initial stage of role adaptation for newly graduated registered nurses. J Advan Nurs 65: 11031113

30. Hezaveh MS, Rafii F, Seyedfatemi N (2013) Experiences of unpreparedness at the beginning of the work. Glob J Health Sci 6: 215-222.

31. Casey K, Fink RR, Krugman AM, Propst FJ (2004) The Graduate Nurse Experience. JONA: J Nurs Admin 34:303-311. 